\title{
The properties of lubricated friction pairs with diamond-like carbon coatings
}

https://doi.org/10.1515/eng-2020-0075

Received Dec 10, 2019; accepted Apr 28, 2020

\begin{abstract}
The purpose of the study was to evaluate the properties of diamond-like carbon DLC coatings with ionic liquids and cutting fluid containing zinc aspartate used as lubricants. The DLC coatings $(\mathrm{a}-\mathrm{C}: \mathrm{H})$ were deposited onto the $100 \mathrm{Cr} 6$ steel substrate by physical vapour deposition PVD. The surface morphology testing, cross section and chemical composition analyses of the DLC coatings were performed using the scanning electron microscope, equipped with an EDS microanalyzer. Surface geometry measurements prior to and after tribological tests were performed on a confocal microscope with interferometry. The tribological tests were carried out on an Anton Paar TRB ${ }^{3}$ tribometer under technically dry friction and lubricated conditions with an ionic liquid, trihexyltetradecylphosphonium bis (trifluoromethylsulfonyl) imide and 1-butyl3-methylimidazolium bis (trifluoromethylsulfonyl) imide and cutting fluid with zinc aspartate. The results show that DLC coatings and ionic liquids can significantly reduce resistance to motion.
\end{abstract}

Keywords: diamond-like carbon coating, ionic liquids, cutting fluid with zinc aspartate, coefficient of friction

\section{Introduction}

Diamond-like carbon coatings DLC have attracted a lot of interest in recent years. Today, they are used in almost every branch of industry, from electronics, mechanical equipment, microelectromechanical circuits to optics [1] and medicine [2]. Diamond-like coatings have very good physical, chemical [1] and tribological properties, in particular: low friction coefficient, high resistance to wear and high hardness [1, 3-5]. Another advantage of diamond-like

\footnotetext{
`Corresponding Author: Joanna Kowalczyk: Kielce University of Technology Kielce, Poland; Email: jkowalczyk@tu.kielce.pl Krystian Milewski: Trzuskawica S. A.

Monika Madej, Dariusz Ozimina: Kielce University of Technology Kielce, Poland
}

coatings is that they can be applied to almost any engineering material: metals, ceramics and polymers. The first carbon coating with properties similar to diamond was applied by Schmellenmeier in 1953 [1]. In 1971, Aisenberg and Chabot obtained a diamond-like coating from a carbon ion beam [6-10].

DLC is an amorphous, thin film carbon based coating [11]. It is a mixture of carbon atoms with sp3 and sp2 bonds, which are characteristic for diamond and graphite respectively. The ratio of $\mathrm{sp} 2 / \mathrm{sp} 3$ carbon atoms is one of the most important factors influencing the properties of diamond-like coatings [4]. The structural properties of all DLC coatings are similar, but their tribological and mechanical properties differ greatly, and this is influenced by the technique and parameters of the deposition process [5].

Diamond-like coatings are self-lubricating coatings, although their wear is inevitable under technically dry friction conditions. In order to obtain a longer service life, they should operate under lubrication conditions [12].

Apart from reducing wear, friction and emissions, which leads to a reduction in energy consumption, the task of lubricants is also to increase the service life of friction elements. Lubricants and their additives need to be improved to meet the growing challenges of the industry. Taking into account new regulations and legal norms related to environmental protection, modern lubricants should be non-toxic. The proposed solution is the use of ionic liquids as a new generation of lubricants. Wang et al. [13] compared ionic liquids with phosphazene oils, perfluorinated polyethers and paraffin oil with ZDTP. They performed tribological tests for steel - steel system in air and vacuum. They obtained the lowest value of the friction coefficient for the ionic liquid [14].

Ionic liquids ILs consist of large, asymmetrical organic cations and usually inorganic anions. Because of large sizes of their molecules and the nature of the chemical groups of anions, the charges of the ions of these salts are usually dispersed. As a result of the reduction in electrostatic forces between the anion and the cation in these salts, and their asymmetries, it is difficult to form a regular crystalline structure and so they can be liquid at room

əopen Access. @ 2020 J. Kowalczyk et al., published by De Gruyter. (Cc) BY 4.0 License 
temperature. ILs were first used as electrolytes in batteries. Thanks to their unique properties, they were used in chemical reactions as "green" solvents. In addition, ionic liquids are miscible with organic compounds. Ionic liquids and their method of production are also considered in some cases to be more environmentally friendly in comparison to the currently used solvents and electrolytes [15]. In 2001, ionic liquids were used for the first time as lubricants [16]. Ever since then the number of published articles on the subject has been constantly growing. Ionic fluids have a number of advantages that allow them to act as lubricants. Their low volatility and flammability, as well as their thermal stability, mean that they are able to safely work at elevated temperatures and pressures, which occur at high friction. Minami et al. [17] have shown that ionic fluids have a much higher level of stability than traditional synthetic oil at $200^{\circ} \mathrm{C}$. Another significant advantage of ionic liquids is the variety of anions and cations. It is estimated that there are about one million available combinations, each of which has its own unique properties. This means that ionic liquids can be selected for a specific application. ILs can be designed to mix with a specific base oil, react with the surface, e.g. The elements contained in ionic liquids can react with a metal surface to form a protective tribofilm, can be incorporated into a cation and/or an anion, e.g. P, F or B [15].

The authors of the paper [18] discussed the results of investigations of surface properties and lubrication capacity of five selected ionic liquids: 1) tetrafluoroborate 1- benzyl-3-methylmidazolium, 2) bis (trifluoromethylsulfonyl) imide 3-methyl-1- propylpyridinium, 3) bis (trifluoromethylsulfonyl) imide 1,2-dimethyl-3propylimidazolium, 4) bis (trifluoromethylsulfonyl) imide trihexyltetradecylphosphonium, 5) tetrafluoroborate trihexyltetradecylphosphonium which they compared to the high quality gear oil: mobilube 1SHC 75W90 and two base oils: PAO-6 and SN-650. The results showed better lubricating properties of ionic fluids compared to base oils, and properties comparable to high quality gear oil. The results of these tests confirmed the possibility of using selected ionic liquids as new lubricating substances.

In the publication [19] the scientists presented the results of investigations under conditions of lubrication with 1-butyl-3-methylimidazolium tetrafluoroborate ionic liquid and during technically dry friction. The use of ionic liquid as a lubricant improved the frictional properties of the systems and the presence of tungsten in amorphous, hydrogenated diamond-like coatings caused the improvement of tribological properties.

The authors of the publication [20] compared the ionic liquids: 1-butyl-3-methylimidazolium tetrafluoroborate with trihexyltetradecylphosphonium bis (trifluoromethylsulfonyl) imide. Additionally, they performed tests under technically dry friction conditions as a reference system for tribological tests with ionic liquids. They showed that the use of diamond-like coatings significantly improved tribological properties, which were additionally increased during the use of ionic liquids.

Yan et al. [21] were conducted the tribological tests on a ball-on-disc tribometer in rotation mode under a dry sliding condition and lubricated conditions with the ILs. The experiments were conducted for an Cr-GLC coatings were deposited on the $9 \mathrm{Cr} 18$ steel and Si wafer by PVD, and the Cr-DLC coatings were deposited on these substrates by PECVD. The counterpart ball was made of $9 \mathrm{Cr} 18$ steel. The results show that the friction coefficient was reduced by approximately $40 \%$ compared with that under the dry condition, and the composite system exhibited a good synergistic lubrication effect. The Cr-DLC coating showed better tribological behaviour than the Cr-GLC coating, which can be ascribed to a better physicochemical film formation under friction and the compact microstructure of the Cr-DLC coating. The synergistic effect of the composite systems was affected by the viscosity and corrosiveness of the ILs and the microstructure of the coatings.

This paper compares two ionic liquids: trihexyltetradecylphosphonium bis (trifluoromethylsulfonyl) imide and 1-butyl-3-methylimidazolium tetrafluoroborate and proecological cutting fluid with zinc aspartate. The biodegradable zinc aspartate was used as a cutting fluid additive. Since it is able to impart such desirable characteristics as wear and corrosion resistance, it can replace the most commonly used zinc dialkyldithiophosphates (ZDDPs), which are toxic. Zinc aspartate is also a zinc based compound but of plant origin. Zinc aspartate has been used mainly in medicine and pharmacology, not as a lubricant additive, with this being the novelty of the research. This research was undertaken in response to the current needs of the machining industry for nontoxic cutting fluids that are safe to humans and the environment as well as lubricants with better properties. As a samples were used disc and ball made of 100Cr6 steel were coated with a diamond-like coating of a-C:H. In the papers presented above no one used the ball with DLC coating.

The literature review above shows that there are large gaps in coolant research. To date, no studies have been conducted to use cutting fluid containing zinc aspartate during tribological tests where both disc and ball with deposited thin, hard coatings, which proves the innovation of the research. 
Table 1: Structures and selected properties of the analysed ionic liquids

\begin{tabular}{|c|c|c|c|c|c|}
\hline Symbol & Chemical name Polish/English & $\begin{array}{l}\text { Summary } \\
\text { formula }\end{array}$ & Structural formula & $\begin{array}{c}\text { Molecular } \\
\text { mass, } \mathrm{g} / \mathrm{mol}\end{array}$ & $\begin{array}{l}\text { Density, } \\
\mathrm{g} / \mathrm{cm}^{3}\end{array}$ \\
\hline IL1 & $\begin{array}{l}\text { bis (trifluorometylo sulfonylo) imide } \\
\text { triheksylotetra decylofosfoniowy/ } \\
\text { trihexyltetradecylphosphonium bis } \\
\text { (trifluoromethylsulfonyl) imide }\end{array}$ & $\begin{array}{c}{\left[\mathrm{CH}_{3}\left(\mathrm{CH}_{2}\right)_{5}\right]_{3} \mathrm{P}[\mathrm{N}} \\
\left.\left(\mathrm{SO}_{2} \mathrm{CF}_{3}\right)_{2}\right] \\
\left(\mathrm{CH}_{2}\right)_{13} \mathrm{CH}\end{array}$ & $\begin{array}{c}\left(\mathrm{CH}_{2}\right)_{5} \mathrm{CH}_{3} \\
1 .+ \\
\mathrm{H}_{3} \mathrm{C}\left(\mathrm{H}_{2} \mathrm{C}\right)_{5}-\mathrm{P}_{+}^{-}-\left(\mathrm{CH}_{2}\right)_{13} \mathrm{CH}_{3} \\
\quad\left(\mathrm{CH}_{2}\right)_{5} \mathrm{CH}_{3} \\
\quad \mathrm{~F}_{3} \mathrm{CO}_{2} \mathrm{~S}^{-N_{-}^{-}}-\mathrm{SO}_{2} \mathrm{CF}_{3}\end{array}$ & 764 & 1.07 \\
\hline IL2 & $\begin{array}{l}\text { tetrafluoroboran 1-butylo-3 } \\
\text { metyloimidazoliowy/ } \\
\text { 1-butyl-3-methylimidazolium } \\
\text { tetrafluoroborate }\end{array}$ & $\mathrm{C}_{8} \mathrm{H}_{15} \mathrm{~N}_{2} \mathrm{BF}_{4}$ & $\widehat{C H}^{\mathrm{CH}_{3}}$ & 226 & 1.21 \\
\hline
\end{tabular}

Table 2: Properties of the cutting fluid containing zinc aspartate

\begin{tabular}{ccccc}
\hline Colour & Smell & $\mathrm{pH}$ & $\begin{array}{c}\text { Density, } \\
\mathbf{g} / \mathbf{c m}^{\mathbf{3}}\end{array}$ & $\begin{array}{c}\text { Water } \\
\text { solubility }\end{array}$ \\
\hline from orange to red & specific & 9.5 & 1.25 & solube \\
\hline
\end{tabular}

\section{Test materials}

$100 \mathrm{Cr} 6$ steel discs with a diameter of $42 \mathrm{~mm}$ and a height of $6 \mathrm{~mm}$ and a 100Cr6 steel ball with a diameter of $6 \mathrm{~mm}$ were used. Both the discs and the ball were coated with a diamond-like coating of $\mathrm{a}-\mathrm{C}: \mathrm{H}$ type by PVD physical vapour deposition at $<300^{\circ} \mathrm{C}$.

The tribological tests were performed under technically dry friction conditions and with the following lubrication: trihexyltetradecylphosphonium bis (trifluoromethylsulfonyl) imide ionic liquid (IL1) and 1-butyl-3methylimidazolium tetrafluoroborate (IL2) and a coolant with zinc aspartate (BCCS). Selected properties of ionic liquids are presented in Table 1 and those of the zinc aspartate coolant in Table 2. The coolant contains: alkanolamine borate, biodegradable oligomer based on poly(aspartic acid) (PASP), demineralised water.

\section{Research methodology}

The aim of the study was to evaluate the tribological properties of diamond-like carbon coatings of a-C:H type in technically dry friction conditions and with the use of lubricating agents.

Using the Phenom XL scanning electron microscope equipped with the EDS microanalyzer, the elements included in the composition of samples coated with the a$\mathrm{C}: \mathrm{H}$ coating were observed and identified before and after the tribological tests.
The Leica DCM8 confocal microscope with interferometry mode was used to measure and analyse the geometric structure of the samples before and after friction tests.

The tribological tests were carried out on the $\mathrm{TRB}^{3}$ tribometer working in the ball-disc combination. The tests were carried out with the following parameters:

- frictional association: ball and discs coated with the $\mathrm{a}-\mathrm{C}: \mathrm{H}$ coating,

- $\operatorname{load} \mathrm{P}=20 \mathrm{~N}$,

- sliding speed $\mathrm{v}=0.1 \mathrm{~m} / \mathrm{s}$,

- friction path $\mathrm{s}=1000 \mathrm{~m}$,

- moisture content $50 \pm 19 \%$,

- ambient temperature $\mathrm{T}_{0}=22 \pm 4^{\circ} \mathrm{C}$,

- lubricants: none, ionic liquids: trihexyltetradecylphosphonium bis (trifluoromethylsulfonyl) imide (IL1) and 1-butyl-3-methylimidazolium tetrafluoroborate (IL2) and a cooling lubricant containing zinc aspartate (BCCS).

\section{Study results}

A diamond-like DLC coating of a-C:H type was observed using SEM microscopy. Figure 1a shows the cross-section of a coating deposited on 100Cr6 steel with a thickness measurement of $1.03 \mu \mathrm{m}$. Linear analysis of the distribution of elements in the EDS coating (Figure 1b) showed that the coating consists of carbon, and the interlayer between the substrate and the coating is tungsten and chromium. These elements are used to ensure good adhesion of the coating to the substrate.

Figure 2 shows a map of the distribution of individual elements together with the EDS characteristic radiation spectrum and the mass content of elements.

The distribution map of elemental concentration (Figure $2 \mathrm{a}$ ) and EDS spectrum (Figure $2 \mathrm{~b}$ ) shows that the coat- 

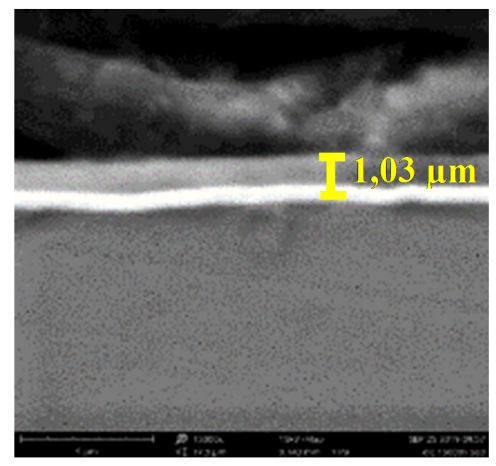

(a)

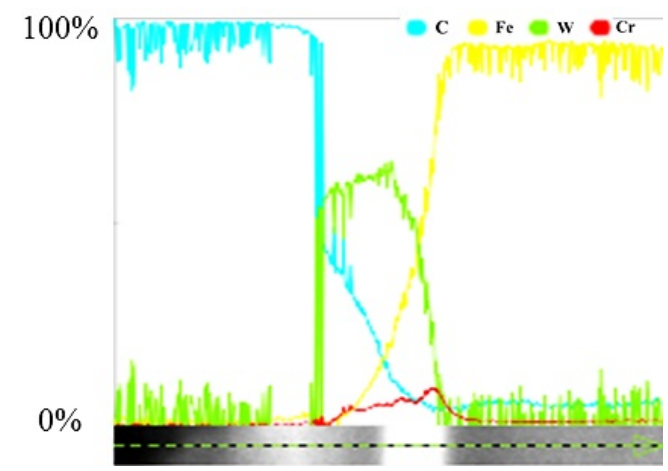

(b)

Figure 1: SEM images: a) microstructure of the a-C:H coating in the cross-section together with the thickness measurement, b) view of the cross-section of the $\mathrm{a}-\mathrm{C}: \mathrm{H}$ coating and linear distribution of the elements making up the coating.
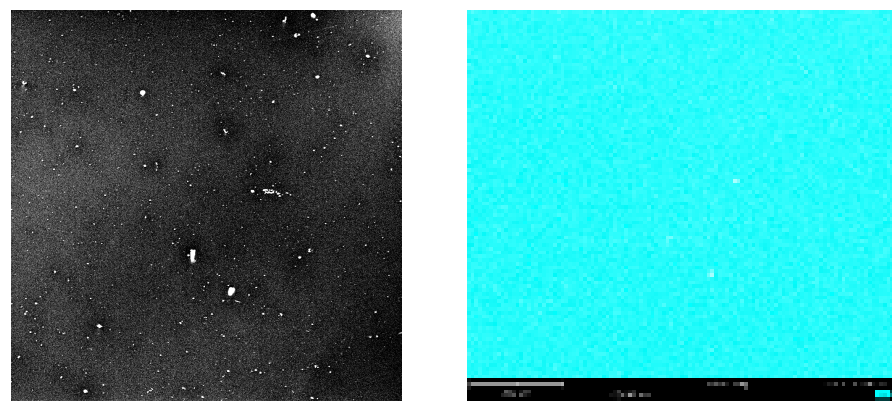

(a)

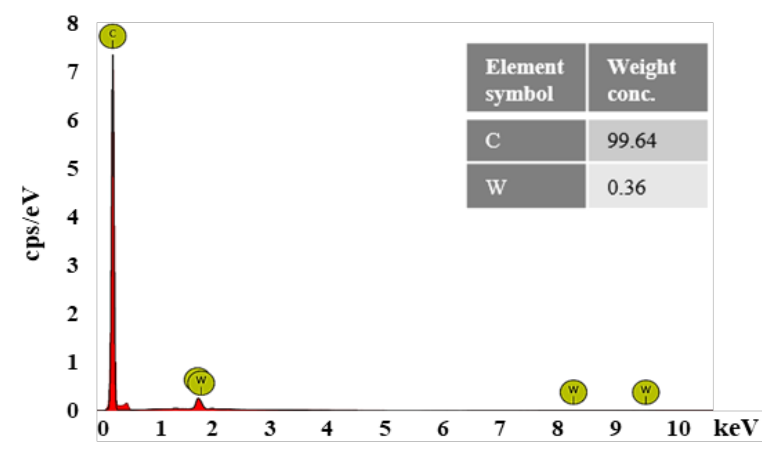

(b)

Figure 2: SEM images: a) view of the coating with a map of element concentration distribution, b) EDS spectrum with mass content of elements.

ing consists mainly of carbon, and in some places tungsten from the interlayer has been additionally observed.

Figure 2 shows a map of the distribution of individual elements together with the EDS characteristic radiation spectrum and the mass content of elements.

The distribution map of elemental concentration (Figure 2a) and EDS spectrum (Figure 2b) shows that the coating consists mainly of carbon, and in some places tungsten from the interlayer has been additionally observed.
Before the tribological tests, the geometric structure of the steel surface of the discs and ball with the a-C:H coating was measured (Figure 3 and 4). An isometric image is shown in Figure 3a and a primary profile in Figure 3b, which suggest that the disc has a homogeneous surface with small indentations of approximately $40 \mathrm{~nm}$ that may have formed during sample preparation. 


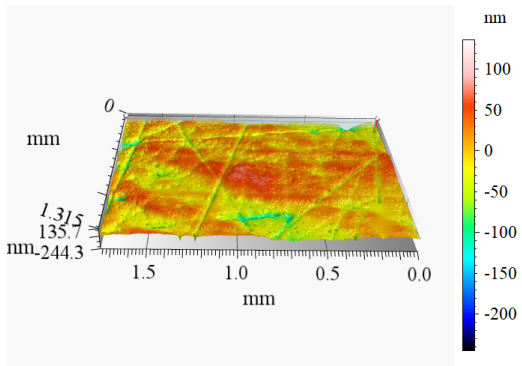

(a)

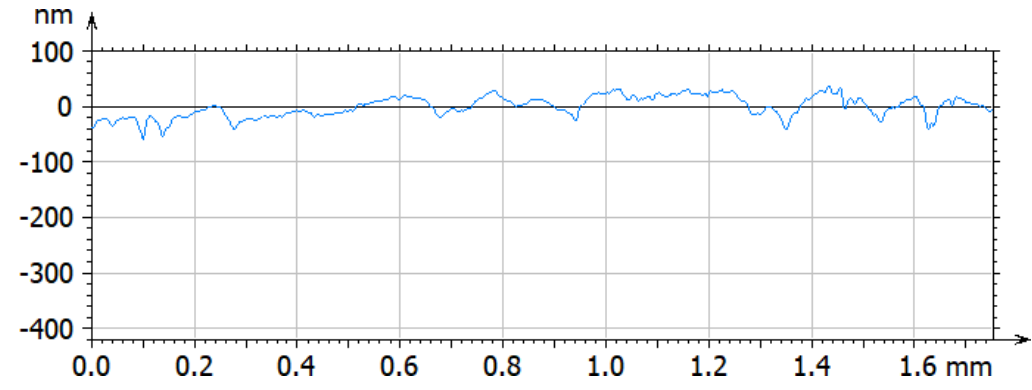

(b)

Figure 3: Geometric structure of $100 \mathrm{Cr} 6$ steel disk with the $\mathrm{a}-\mathrm{C}: \mathrm{H}$ coating: a) isometic image, b) primary profile.

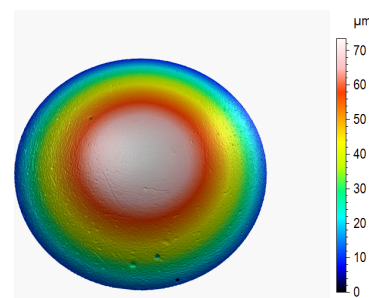

(a)

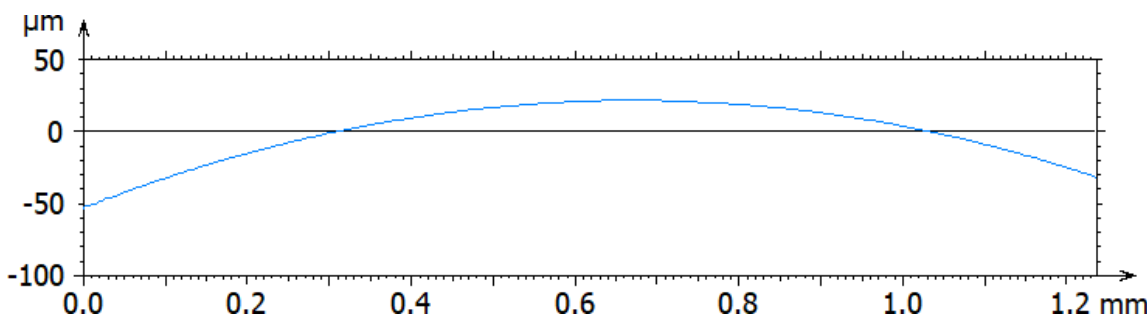

(b)

Figure 4: Geometric structure of $100 \mathrm{Cr} 6$ steel ball with the a-C:H coating: a) isometic image, b) primary profile.

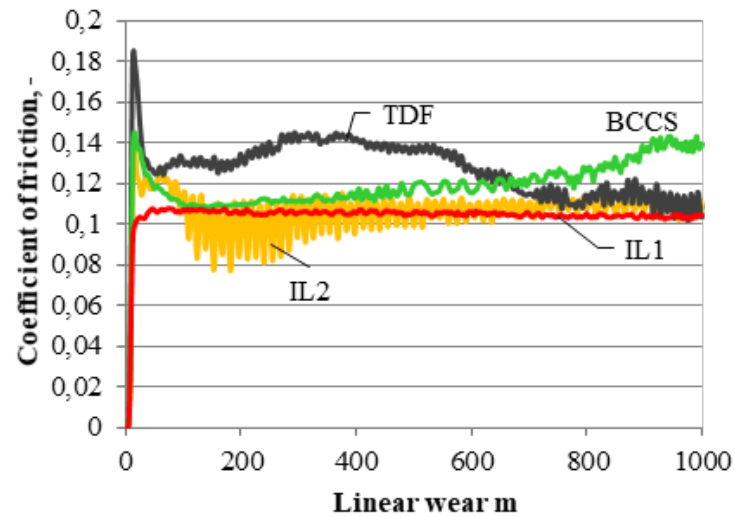

(a)

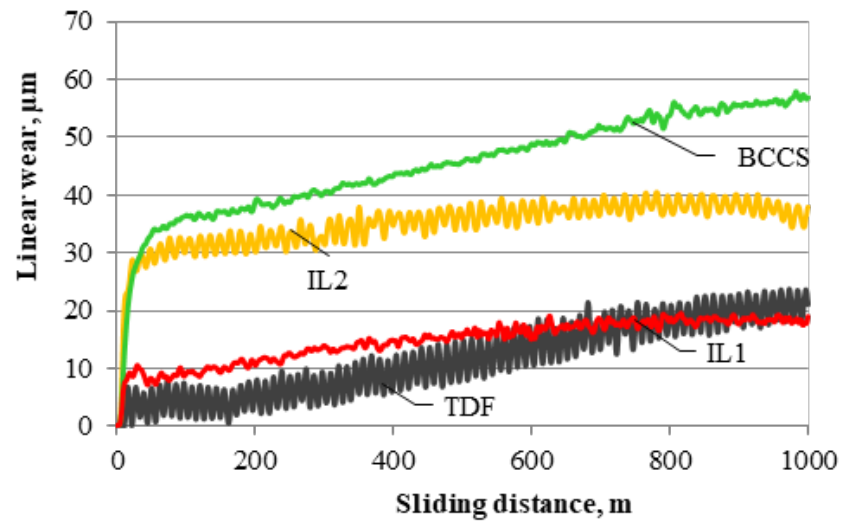

(b)

Figure 5: Tribological characteristics depending on the lubricant: a) coefficient of friction, b) linear wear.

Figure 5 shows the results of the tribological tests: mean coefficient of friction (Figure 5a) and intensity of linear wear (Figure 5b).

The lowest value of the coefficient of friction and linear wear was recorded after friction with the lubrication utilizing the trihexyltetradecylphosphonium bis (trifluoromethylsulfonyl) imide ionic liquid (IL1). On the other hand, the highest value of the mean coefficient of friction and linear wear was observed after friction with lubrication with a coolant containing zinc aspartate (BCCS). The ionic liquid (IL1) used for the tests decreased the coefficient of friction and linear wear in comparison with technically dry friction (TDF).

After the tribological tests, the samples and countersamples were subjected to observations on a confocal microscope with interferometry mode. The geometric structure of the surface of the discs (Figure 6) and balls (Figure 7) in the abrasion areas was analysed and the maximum depth and area of the abrasion surface were determined (Table 3). 


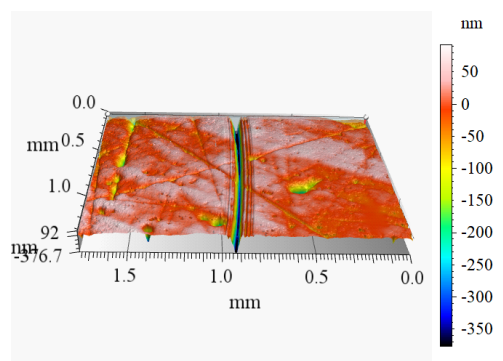

(a)

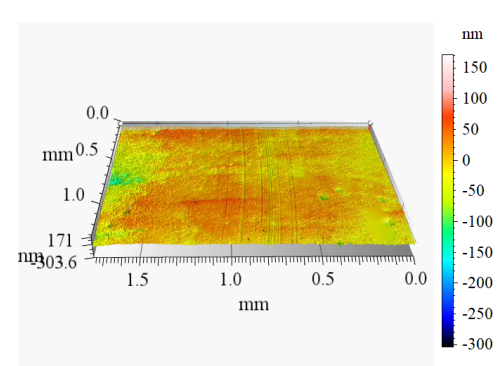

(b)

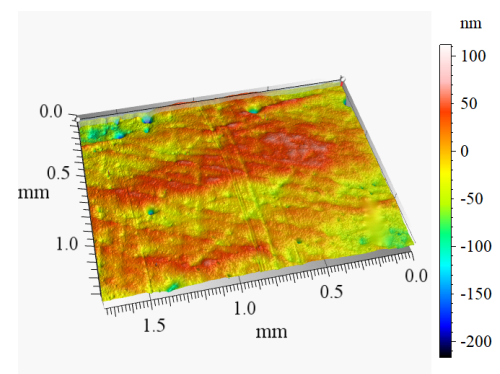

(c)

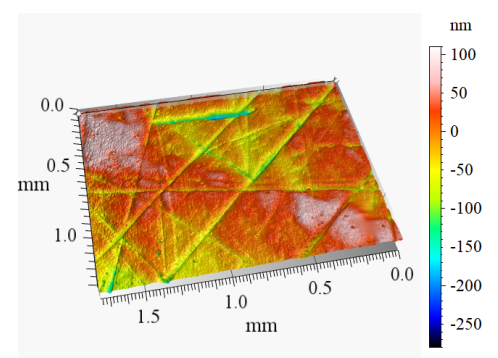

(d)
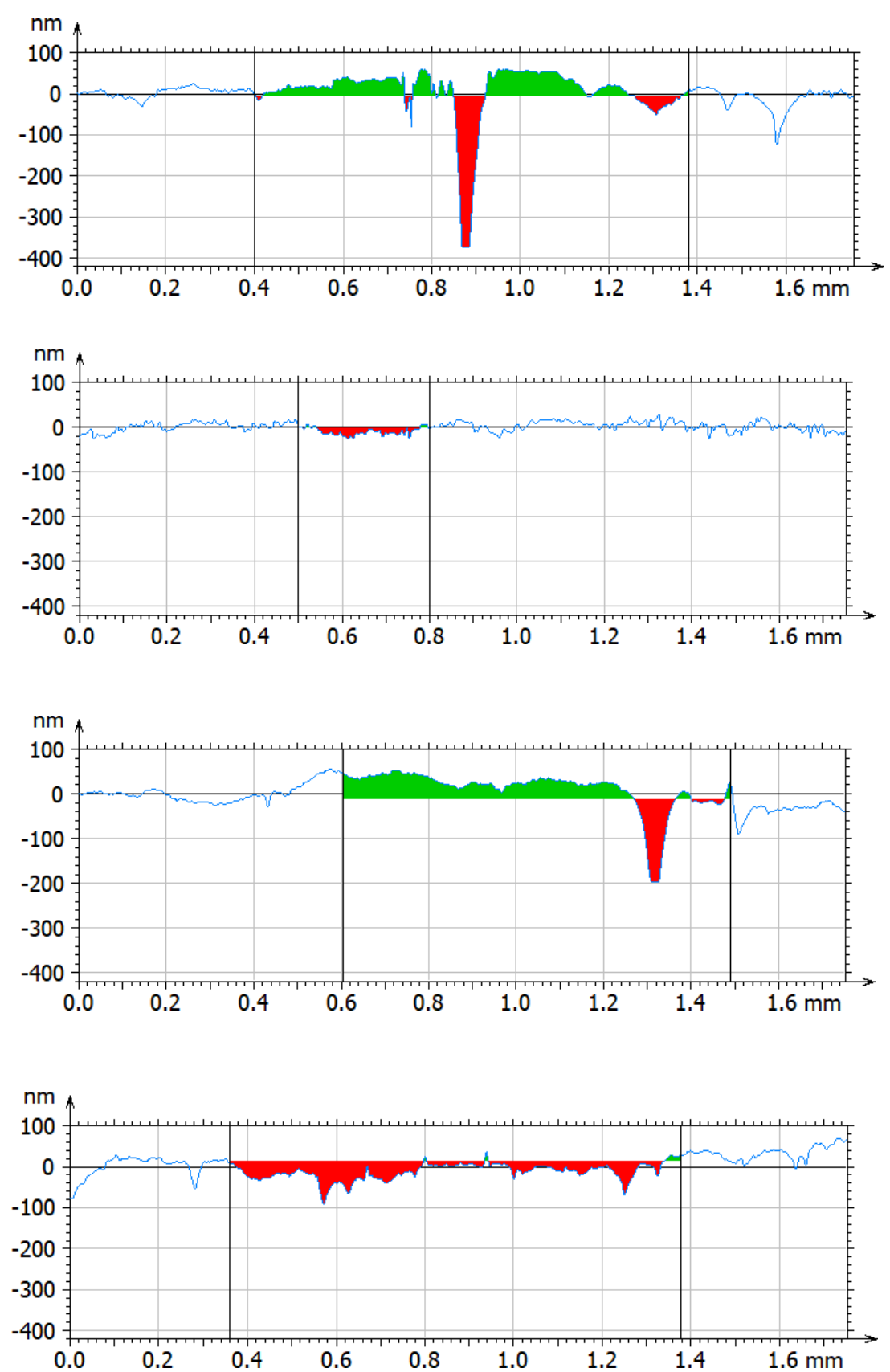

Figure 6: Isometric image and primary profile disks after tribological tests in the following conditions: a) TDS, b) IL1 lubrication, c) IL2 lubrication, d) BCCS lubrication.

Table 3: Maximum depth and surface area of the disk and ball.

\begin{tabular}{ccccccccc}
\hline \multirow{2}{*}{ Parameters } & \multicolumn{2}{c}{ TDF } & \multicolumn{2}{c}{ IL1 } & \multicolumn{2}{c}{ IL2 } & \multicolumn{2}{c}{ BCCS } \\
\cline { 2 - 9 } & disk & ball & disk & ball & disk & ball & disk & ball \\
\hline Maximal depth, $\boldsymbol{\mu m}$ & 0.37 & 1.64 & 0.03 & 0.001 & 0.20 & 0.08 & 0.10 & 0.07 \\
Surface area $\boldsymbol{\mu m}^{2}$ & 17.79 & 13.08 & 3.81 & 0.001 & 12.05 & 0.24 & 17.96 & 5.85 \\
\hline
\end{tabular}




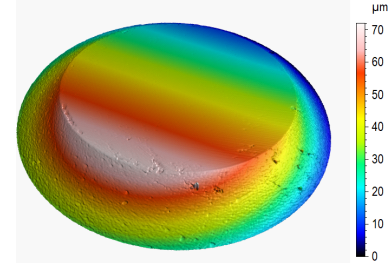

(a)

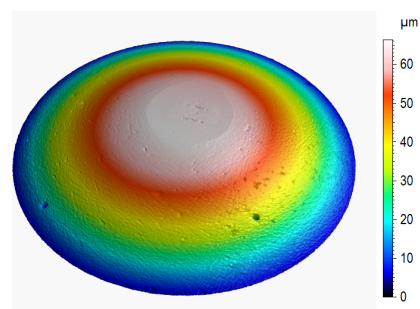

(b)

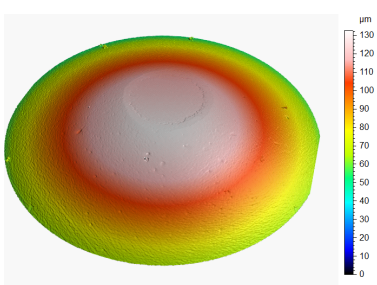

(c)

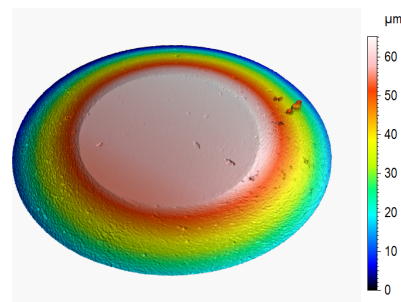

(d)
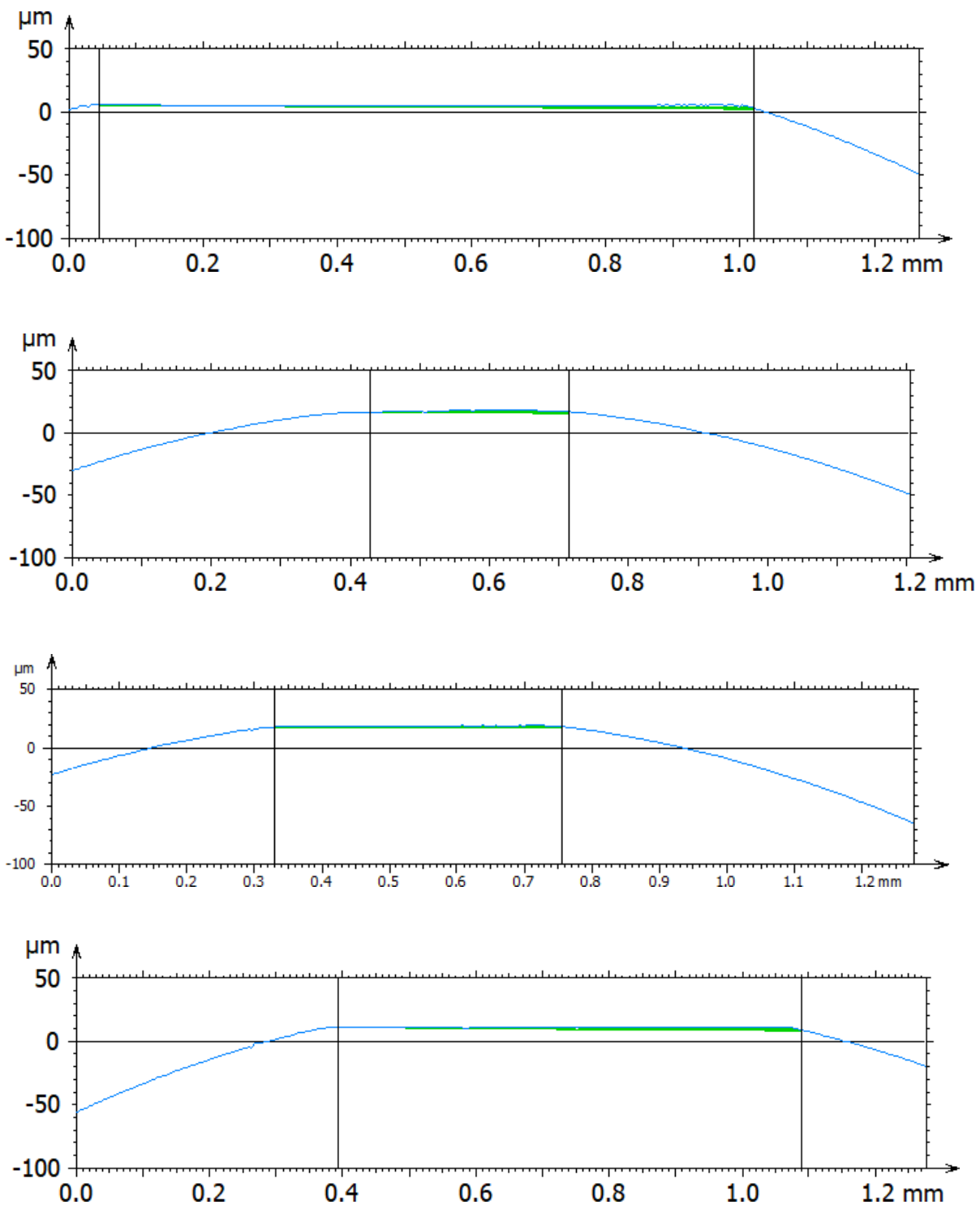

Figure 7: Isometric image and primary profile balls after tribological tests in the following conditions: a) TDS, b) IL1 lubrication, c) IL2 lubrication, d) BCCS lubrication.

Comparing the disc abrasion profiles, it was observed that the deepest trace and the depth of abrasion was observed after technically dry friction (Figure 6a). However, the shallowest and the smallest trace, occupying the smallest abrasion area, was obtained after friction in the conditions of lubrication utilizing the trihexyltetradecylphosphonium bis (trifluoromethylsulfonyl) imide ionic liquid (IL1) (Figure 6c).

The highest depth and abrasion area of the ball was recorded after technically dry friction (Figure 7a). The diameter of the abrasion on the ball was about $1 \mathrm{~mm}$. On the other hand, the smallest depth, area and abrasion diameter of about $0.3 \mathrm{~mm}$ were obtained for the ball after friction utilizing lubrication with trihexyltetradecylphosphonium bis (trifluoromethylsulfonyl) imide ionic liquid (IL1) (Figure 7c).

The geometrical structure of the surface has a great impact on the operational properties of machine and device components in order to find new durable materials [22, 23]. The quantitative assessment of the geometric structure of the surface is made on the basis of conventionally accepted parameters, which are determined for the primary profile and isolated from this profile by filtration of roughness and corrugation profiles. For example, electric filters are most often used to separate the roughness profile and 
Table 4: Roughness parameters discs before and after tribological tests.

\begin{tabular}{ccccccccc}
\hline \multirow{2}{*}{ Test } & \multirow{8}{*}{ Sample/counter-sample } & \multicolumn{7}{c}{ Roughness parameters of surface } \\
\cline { 3 - 9 } & & $\mathbf{S a}$ & $\mathbf{S q}$ & $\mathbf{S p}$ & $\mathbf{S v}$ & $\mathbf{S z}$ & Ssk & Sku \\
& & $\mathbf{n m}$ & $\mathbf{n m}$ & $\mathbf{n m}$ & $\mathbf{n m}$ & $\mathbf{n m}$ & - & - \\
\hline \multirow{2}{*}{ Before tests } & Disk & 21.8 & 28.1 & 89.6 & 147 & 237 & -0.6 & 3.4 \\
& Ball & 982.9 & 1159 & 1973 & 2827 & 4801 & -181.3 & 2090 \\
TDF & Disk & 45.5 & 76.6 & 97.1 & 372 & 469 & -3.0 & 12.3 \\
& Ball & 3847 & 4527 & 9109 & 9065 & 18170 & -18.57 & 1993 \\
IL1 & Disk & 13.5 & 16.7 & 83.9 & 156 & 240 & -0.2 & 3.5 \\
& Ball & 1022 & 1218 & 1837 & 3228 & 5065 & -523.8 & 2296 \\
IL2 & Disk & 17.5 & 21.5 & 66.1 & 163 & 229 & -0.2 & 3.0 \\
& Ball & 3048 & 3585 & 7260 & 7009 & 14270 & 53.04 & 1973 \\
BCCS & Disk & 27.1 & 36.5 & 122 & 263 & 385 & -1.6 & 9.0 \\
& Ball & 885.5 & 1042 & 2089 & 2608 & 4497 & 21.53 & 1992 \\
\hline
\end{tabular}

the wavy profile. Surface topography is like a graphic or network environment [23-25].

Table 4 presents the parameters of the geometric structure of the surface of discs and balls before and after tribological tests. After analysis of the parameters of the geometric structure of the disc surface (Table 4) before and after tribological tests it was found that the lowest values of the parameters $\mathrm{Sa}$ - arithmetic mean of the surface height and $\mathrm{Sq}$ - mean square height of the surface were obtained after tribological tests in the conditions of lubrication utilizing the trihexyltetradecylphosphonium bis (trifluoromethylsulfonyl) imide ionic liquid (IL1), which prove that the smooth surface of the disc was obtained at the abrasion point. The lowest values of the parameters $\mathrm{Sp}$ - maximum height of the surface peak and $\mathrm{Sz}$ - maximum height of the surface were observed after the studies with ionic liquid lubrication with 1-butyl-3-methylimidazolium tetrafluoroborate (IL2). The Ssk parameters - coefficient of surface inclination (asymmetry) had negative values in all cases, which characterizes surfaces with plateau elevations. The lowest values of these parameters were obtained for ionic liquids. Whereas the Sku parameter - the surface slope coefficient - kurtosis is a measure of the smoothness of the distribution curve of ordinates, also called the coefficient of concentration. For normal (Gaussian) ordinates distribution the $S k u=3[24,25]$. After friction under lubrication conditions (IL2) a normal distribution was obtained, and for the disc before tests and after friction with lubrication (IL1) a distribution of ordinates close to normal was obtained. Different values were obtained for technically dry friction (TDF) $-\mathrm{Sku}=12.3$ and coolant lubrication with zinc aspartate $(\mathrm{BCCS})-\mathrm{Sku}=9$. Positive values indicate steep unevenness and defects on these surfaces.
After comparison of the obtained parameters of the geometric structure of the ball surface and after tribological tests it was found that the lowest values of the parameters $\mathrm{Sa}$ - arithmetic mean of the surface height, Sq - mean square height of the surface, $\mathrm{Sv}$ - maximum depth of the surface cavities and $\mathrm{Sz}$ - maximum height of the surface were obtained after tribological tests under friction conditions with lubrication with a coolant containing zinc aspartate (BCCS), which prove that the smooth ball surface was obtained at the abrasion point. The lowest values of the parameters $\mathrm{Sp}$ - maximum height of the surface peak - were observed after tests under conditions of lubrication utilizing the trihexyltetradecylphosphonium bis (trifluoromethylsulfonyl) imide ionic liquid (IL1). The parameters Ssk - the coefficient of surface inclination (asymmetry) after technically dry friction and under conditions of lubrication utilizing the trihexyltetradecylphosphonium bis (trifluoromethylsulfonyl) imide (IL1) had a negative value characterizing surfaces with plateau elevations. On the other hand, after friction under 1-butyl3-methylimidazolium tetrafluoroborate ionic liquid (IL2) and coolant (BCCS) lubrication conditions, the values of the Ssk parameter were positive, which proves that a smooth surface without deep scratches was obtained. The Sku parameter - the surface inclination coefficient - kurtosis is a measure of the slenderness of the distribution curve. The lowest value of this parameter was obtained for the ball after friction under coolant (BCCS) lubrication conditions. Positive kurtosis values indicate steep unevenness and the occurrence of defects on these surfaces.

Figure 8 shows the SEM images of the discs in the abrasion areas after tribological tests. After technically dry friction at the selected point of wear trace on the ball, the following elements included in the diamond-like coating 

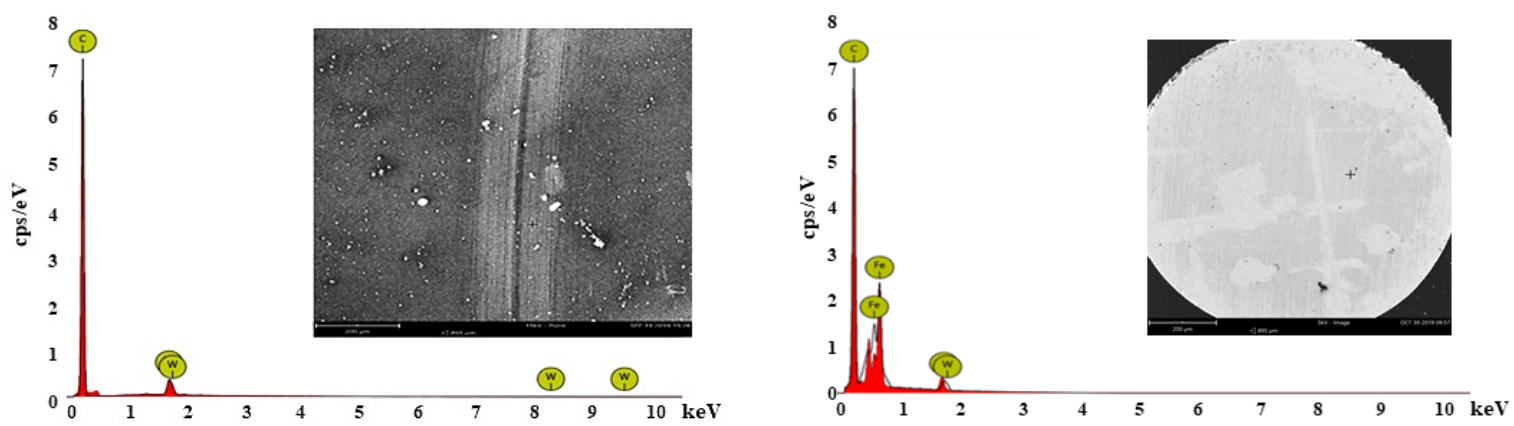

(a)
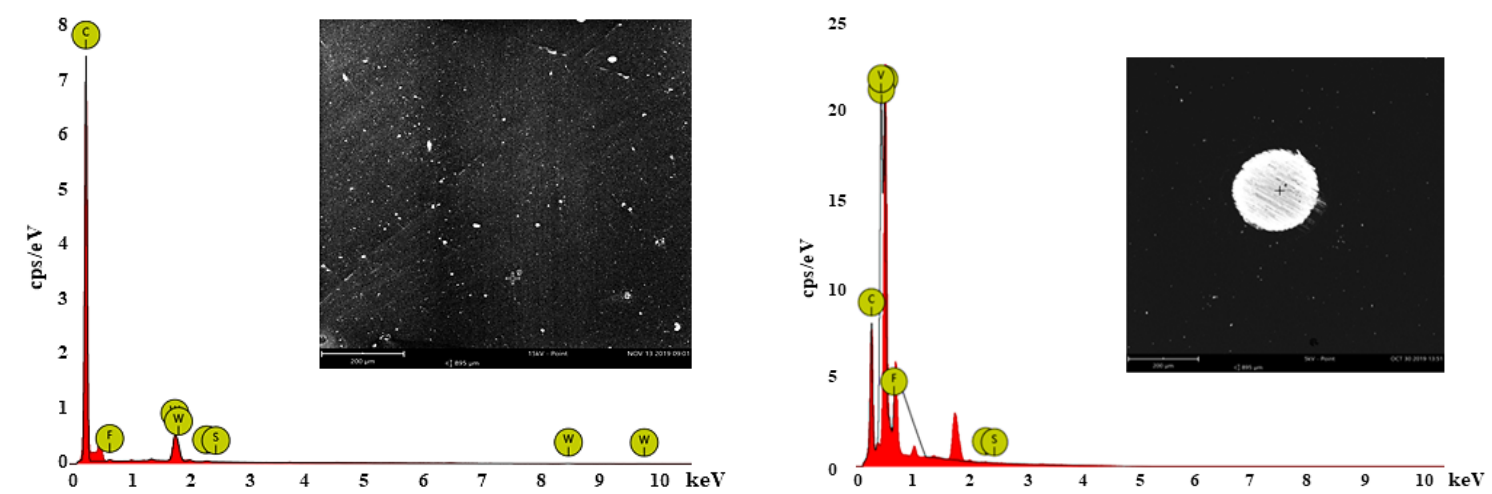

(b)
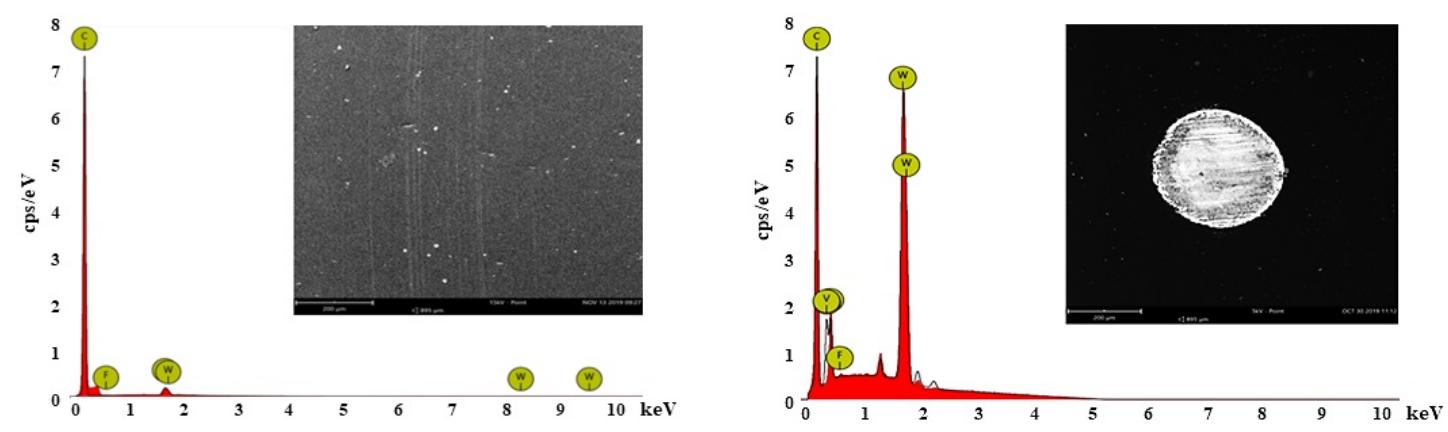

(c)
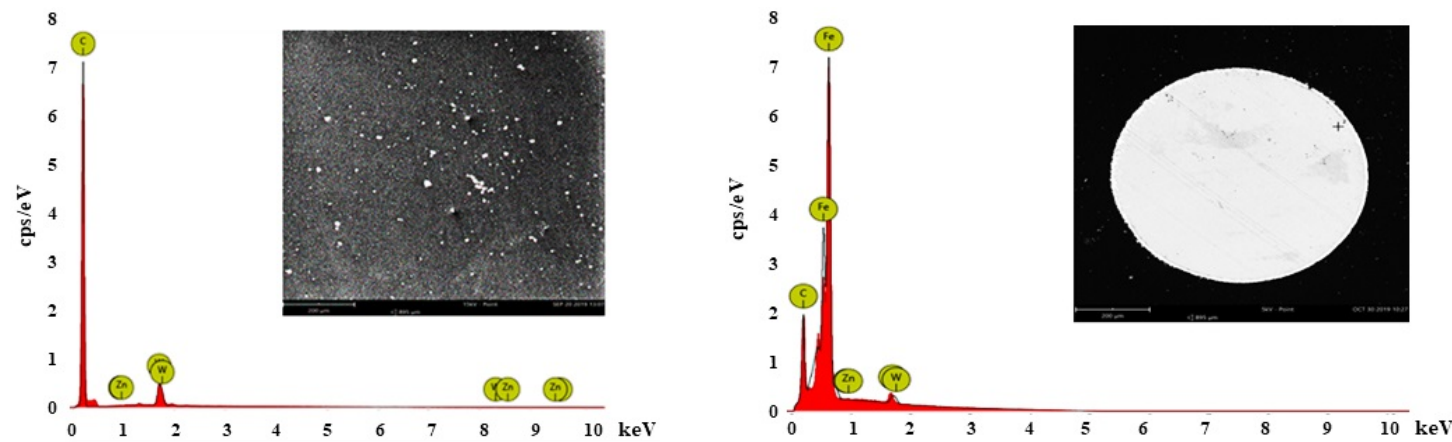

(d)

Figure 8: View of the wear trace of the disc and ball and point analysis of the elements after frictional cooperation in the following conditions: a) TDF, b) IL1 lubrication, c) IL2 lubrication, d) BCCS lubrication. 
were found: carbon and tungsten, as well as iron (on the ball), which comes from the substrate. After friction with lubrication utilising the tested lubricating substances, in addition to the elements included in the DLC coating, the following additional elements from the lubricating agents used in the tests were observed:

- fluorine and sulphur from the trihexyltetradecylphosphonium bis (trifluoromethylsulfonyl) imide ionic liquid (IL1) both on the disc and on the ball,

- fluorine from the 1-butyl-3-methylimidazolium tetrafluoroborate ionic liquid (IL2) - on the disc and the ball,

- zinc from the coolant containing zinc aspartate (BCCS) - on the disc and the ball.

This may indicate the formation of wear-resistant top layers also on the surface of the ball.

During friction, surface layers are formed as a result of physical and chemical process called tribochemicals reactions. They occur mainly between the enriching additives contained in lubricants and friction co-operating surfaces. The surface layer generated in this way reduces friction and extends the service life of the cooperating friction pair elements.

\section{Conclusions}

The research carried out in this paper is consistent with contemporary issues related to the search for more and more durable materials and modern lubricants.

The results of surface topography tests showed a very good quality of a-C:H coatings resulting from a wellprepared 100Cr6 steel substrate.

Surface morphology and chemical composition of a$\mathrm{C}: \mathrm{H}$ coatings confirmed the presence of carbon in their composition, as well as the presence of an interlayer consisting of tungsten and chromium.

Diamond-like coatings of a-C:H type under conditions of lubrication utilizing the trihexyltetradecylphosphonium bis (trifluoromethylsulfonyl) imide ionic liquid affected not only the decrease of the friction coefficient and linear wear, but also lower wear of the analysed disc and ball surface. As a results of forming surface layers containing additives from lubricants.

The performance of the trihexyltetradecylphosphonium bis (trifluoromethylsulfonyl) imide ionic liquid when in contact with the a-C:H coating was better than that of the 1-butyl-3-methylimidazolium tetrafluoroborate ionic liquid and the coolant containing zinc aspartate.

From the isometric views, primary profiles and roughness parameters obtained for the discs after the tribological tests, it is evident that the use of the trihexyltetradecylphosphonium bis (trifluoromethylsulfonyl) imide ionic liquid resulted in the shallowest, the smallest wear track and the lowest values of the amplitude parameters.

After friction tests in the conditions of lubrication utilizing ionic liquids and non-toxic coolant on the disc and the ball, elements included in the lubricating greases used in the tests were found in selected points. This may indicate the formation of wear-resistant top layers and requires further research. The direction of further research is to perform tests with other lubricants.

\section{References}

[1] Zahid R, Masjuki BHH, Varmana M, Mufti RA, Kalam MA, Zulkiflia NWBM, Gulzar M. A review on effects of lubricant formulations on tribological performance and boundary lubrication mechanisms of non-doped DLC/DLC contacts. Crit rev solid state. 2017;42(4):267-294.

[2] Zhao YY, Zhao B, Su X, Zhang S, Wang S, Keatch R, Zhao Q. Reduction of bacterial adhesion on titanium-doped diamond-like carbon coatings. Biofouling. 2018;34(1):26-33.

[3] Ghadai RK, Kalita K, Mondal SCh, Swain BP. PECVD process parameter optimization: towards increased hardness of diamondlike carbon thin films. Mater manuf process. 2018;33(16):190513.

[4] Chang SH, Lai YCh, Huang KT, Liu ChM. Characteristics of DLC/oxynitriding duplex-treated V8 tool steel by DC-pulsed PECVD. Surf. Eng. 2019:1-8.

[5] Ghadai RK, Kalita K, Mondal SCh, Swain BP. Genetically optimized diamond-like carbon thin film coatings. Mater Manuf Process. 2019;34(13):1476-1487.

[6] Aisenberg S, Chabott R. Ion-Beam Deposition of Thin Films of Diamondlike Carbon. J Appl Phys. 1971;42:2953.

[7] Żelazko J. Wpływ parametrów technologicznych na właściwości epitaksjalnych warstw węglowych osadzanych z fazy gazowej na podłożach krzemowych. Materiały Elektroniczne. 2004;32:1-4.

[8] Mashayekhi F, Shafiekhani A, Sebt SA, Darabi E. The effect of initial pressure on growth of FeNPs in amorphous carbon films. Int. Nano Lett. 2018;13(8):25-30.

[9] Milewski K, Kudlinski J, Madej M, Ozimina D. The inter-action between diamond like carbon (DLC) coatings and ionic liquids under boundary lubrication conditions. Metalurgija. 2017;56:558.

[10] Wada N, Gaczi PJ, Solin SA. Diamond-Like 3-Fold Coordinated Amorphous Carbon. J Non-Cryst Solids. 1980;35-36:543-8.

[11] Mishra T, Nordin B, Svanbäck D, Tervakangas S, Prakash B. The effects of contact configuration and coating morphology on the tribological behavior of tetrahedral amorphous diamond-like carbon (ta-CDLC) coatings under boundary lubrication. Tribology - Materials, Surfaces \& Interfaces. 2019;13(2):120-9. 
[12] Zeng Q. Superlow friction and diffusion behaviors of a steelrelated system in the presence of nano lubricant additivein PFPE oil. J Adhes Sci Technol. 2019;33(9):1001-18.

[13] Wang H, Lu Q, Ye Ch, Liu W, Cui Z. Friction and behaviors of ionic liquid of alkylimidazoliumhexafluorophosphates as lubricanys for steel/steel contact. Wear. 2004; 256:44-8.

[14] Ozimina D. Eksploatacja systemów tribologicznych. Tom I. Znaczenie tribologii w eksploatacji obiektów technicznych M48. Kielce:Wyd PŚk; 2013.

[15] Somers AE, Howlett PC, Mac Farlane DR, Forsyth M. A Review of Ionic Liquid Lubricants. Lubricants. 2013;1:3-21.

[16] Ye C, Liu W, Chen Y, Yu L. Room-Temperature ionic liquids: A novel versatile lubricant. Chemical Communications. 2001;21:2244-5.

[17] Minami I, Kamimuram H, Mori S. Thermo-Oxidative stability of ionic liquids as lubricating fluids. J Synthetic Lubric. 2007;24(3):135-47.

[18] Kałdoński TJ, Stańczyk M, Gryglewicz Ł, Kałdoński T. Initial studies on lubricity and surface properties of selected ionic liquids. Journal of KONES. 2011;18(1):213-26.

[19] Madej M, Marczewska-Boczkowska K, Ozimina D. Wpływ wolframu na odporność powłok diamentopodobnych stosowanych w przemyśle chemicznym. Przem. Chem. 2014;93(4):500-5.
[20] Madej M, Ozimina D. Wtaściwości tribologiczne powtok diamentopodobnych smarowanych cieczami jonowymi. Tribologia. 2014; 4:73-84.

[21] Yan M, Wanga X, Zhanga S, Zhang S, Sui X, Li W, Hao J, Liu W. Friction and wear properties of GLC and DLC coatings under ionic liquid lubrication. Tribology International. 2020;143:1-11.

[22] Li S. The Art of Clustering Bandits. PhD Dissertation. Insubria: University of Insubria;2016.

[23] Zalewski K, Matuszak J, Zalewski R. Metrologia warstwy wierzchniej. Lublin:Wydawnictwo Politechniki Lubelskie; 2018.

[24] Korda N, Szörényi B, Li S. Distributed Clustering of Linear Bandits in Peer to Peer Networks. ICML'16: Proceedings of the 33rd International Conference on International Conference on Machine Learning. 2016;48:1301-9.

[25] Li S, Karatzoglou A, Gentile C. Collaborative Filtering Bandits. SIGIR '16: Proceedings of the 39th International ACM SIGIR conference on Research and Development in Information Retrieval. 2016;Jul:539-48. 